\title{
Association of macrophage migration inhibitory factor promoter polymorphism $-173 G / C$ with susceptibility to childhood asthma
}

\author{
TAREK Z. EL-ADLY', SALLY KAMAL', HALA SELIM ${ }^{1}$, SHAHIRA BOTROS \\ 'Department of Pediatrics, Cairo University Children's Hospital, Cairo University, Cairo, Egypt \\ ${ }^{2}$ Department of Clinical Pathology, Cairo University, Cairo, Egypt
}

\begin{abstract}
Introduction: Macrophage migration inhibitory factor $(M I F)$ is a proinflammatory cytokine that plays an important role in the pathogenesis of asthma. Polymorphisms associated with inflammatory diseases exist in the promoter region of MIF, which alter its expression. We aimed to study the association of MIF promoter polymorphism $-173 \mathrm{G} / \mathrm{C}$ with childhood asthma.

Material and methods: In this case-control study, we recruited 60 pediatric patients with bronchial asthma and 90 age- and sex-matched healthy controls. MIF-173G/C was genotyped using polymerase chain reaction-restriction fragment length polymorphism (PCR-RFLP).

Results: Genotype distribution between cases and healthy controls was statistically evaluated. Our results revealed that the frequency of the MIF-173C allele was significantly higher in children with asthma than in the control group $(p=0.002$, odds ratio $[O R]=3.61,95 \%$ confidence interval $[C I]=$ 1.63-7.97). The frequency of the MIF-173CC genotype was higher in the asthmatic children than in the controls $(p=0.028, O R=6.24,95 \% C I=1.24-31.29)$. Comparing carriage of the MIF-173C allele in pediatric patients with asthma with that observed in healthy controls $(G C+C C v s . G G)$ revealed a positive association with the disease ( $p=0.019, \mathrm{OR}=3.12,95 \% \mathrm{CI}=1.22-7.99)$.

Conclusions: These results suggest that MIF-173G/C polymorphism confers an increased risk of susceptibility to the development of childhood asthma in an Egyptian population.
\end{abstract}

Key words: children, polymorphism, asthma, promoter, macrophage migration inhibitory factor.

(Cent Eur J Immunol 2016; (3): 268-272)

\section{Introduction}

Asthma is the most common chronic inflammatory disease of childhood, characterized by periodic obstruction of the airways and respiratory symptoms such as wheezing, cough and breathlessness [1]. It affects one child in 7 in some societies and approximately 300 million individuals worldwide. Its prevalence has been increasing in the majority of developed countries, with widespread differences. The reasons for these differences are not known, but almost certainly they reflect variable contributions of genetic and environmental factors in different regions [2]. $\mathrm{T}$ cells and immunoglobulin E (IgE)-mediated responses are the key factors in allergic diseases [3]. Disturbance in the T helper type 1 (Th1)/T helper type 2 (Th2) balance is thought to play a critical role in the pathophysiology of asthma [4]. In response to allergens, the T lymphocytes produce a restricted array of cytokines. The Th2 cells produce the proinflammatory cytokines while Th1 cells are involved in virus defense and antagonism of the allergic response $[4,5]$.

Macrophage migration inhibitory factor (MIF) is a proinflammatory cytokine released from $\mathrm{Th} 2$ cells and macrophages that plays an important role in the pathogenesis of asthma. It was initially described as an immune activity isolated from the supernatants of T lymphocytes and has been implicated in macrophage activation and antigen-driven T cell responses [6, 7]. It has the unique feature of overriding the anti-inflammatory and immunosuppressive effects of glucocorticoids [7]. The MIF gene maps to chromosome 22q11.2 in humans. Functional polymorphisms have been identified in the MIF promoter region: a single nucleotide polymorphism (SNP) at position -173 [guanine (G)-to-cytosine (C) transition] and a CATT ${ }_{5-8}$

Correspondence: Tarek Zakaria El-Adly, Cairo University Children's Hospital, Cairo University, Department of Pediatrics,

72 El-Thawra St., Heliopolis, 11341 Cairo, Egypt, e-mail: doctortarek@ hotmail.com

Submitted: 15.08.2015; Accepted: 15.11.2015 
microsatellite polymorphism at position -794 [8]. Polymorphisms of the human MIF gene have been associated with increased susceptibility to or severity of a number of inflammatory and autoimmune diseases such as juvenile idiopathic and adult rheumatoid arthritis, ulcerative colitis, atopy, sarcoidosis, psoriasis and extensive forms of alopecia areata [8-10].

MIF is involved in antigen-specific immune responses and plays an important role in the development and progression of asthma. Anti-MIF antibodies inhibits T cell proliferation and interleukin-2 production, suppressing antigen-driven $\mathrm{T}$ cell activation and antibody production [11]. Treatment with anti-MIF antibody significantly suppressed airway inflammation and airway hyperresponsiveness in rats with atopic asthma [12]. Polymorphism in the $-173 \mathrm{C}$ allele has been associated with higher transcription activity of the MIF gene and increased production of MIF protein, while the $\mathrm{CATT}_{5}$ allele has the lowest level of basal and stimulated MIF promoter activity in vitro compared with other alleles [8]. So far, the associations between MIF-173G/C promoter polymorphism and asthma have not been fully studied. The functional importance of MIF in immune-mediated inflammatory diseases prompted us to evaluate the association of MIF-173G/C polymorphism with childhood asthma in an Egyptian population.

\section{Material and methods}

\section{Study design and patient population}

In this case-control study, 60 unrelated asthmatic children were recruited from Cairo University Children's Hospital, Cairo University, Egypt, and 90 age-, gender- and ethnicity-matched healthy controls were enrolled when meeting the following criteria: no symptoms or history of asthma or other pulmonary diseases, no symptoms or history of atopy and absence of first-degree relatives with a history of asthma or atopy. Asthma was defined according to the Global Initiative for Asthma (GINA) criteria [13]. The asthmatic children had to fulfill the following two criteria: two or more episodes of wheezing and shortness of breath during the past year, and reversibility of the wheezing and dyspnea, either spontaneously or by bronchodilator treatment. The procedures followed in this study were in accordance with the Helsinki Declaration of 1975 , as revised in 2000 , and the study was ethically approved by the Institutional Review Board of the Faculty of Medicine, Cairo University. All the participants' parents or guardians signed an informed consent form.

\section{Total serum IgE}

Total serum IgE levels were measured by the ACS-180 system (Bayer, New York) and expressed in international units per milliliter (IU/ml).

\section{DNA extraction}

Peripheral blood samples were collected from all patients in vacuum tubes containing ethylene diamine tetraacetic acid (EDTA). Genomic DNA was extracted using the AxyPrep Blood Genomic DNA Miniprep Kit (catalogue number AP-MN-BL-GDA-50; Axygen Biosciences Inc., Ocean City, California, USA) according to the manufacturer's instructions.

\section{MIF-173G/C genotyping}

MIF-173G/C was genotyped by polymerase chain reaction (PCR) and restriction fragment length polymorphism (RFLP). PCR was performed in a total volume of $50 \mu \mathrm{l}$ of solution containing $200 \mathrm{ng}$ of genomic DNA and $0.4 \mu \mathrm{M}$ of each of the following 2 primers: the forward primer was 5'-ACTAAGAAAGACCCGAGGC-3' and the reverse primer was 5'-GGGGCACGTTGGTGTTTAC-3'. Other conditions were as follows: $1.5 \mathrm{mM} \mathrm{MgCl}, 400 \mu \mathrm{M}$ of dNTP, $4 \%$ DMSO, 1 U Taq DNA polymerase, and $1 \mu \mathrm{l}$ 10X PCR buffer (Invitrogen, Carlsbad, CA). The thermal cycling conditions were initial denaturation at $95^{\circ} \mathrm{C}$ for $5 \mathrm{~min}$, followed by 35 cycles at $95^{\circ} \mathrm{C}$ for $30 \mathrm{~s}, 51^{\circ} \mathrm{C}$ for $30 \mathrm{~s}$ and $72^{\circ} \mathrm{C}$ for $30 \mathrm{~s}$, with a final extension at $72^{\circ} \mathrm{C}$ for $10 \mathrm{~min}$. The resulting PCR products of $365 \mathrm{bp}$ were digested with $10 \mathrm{U}$ of $A l u \mathrm{I}$ restriction endonuclease (New England BioLabs, Beverly, MA) overnight at $37^{\circ} \mathrm{C}$. This resulted in 2 fragments of 268 and $97 \mathrm{bp}$ when a $\mathrm{G}$ was present at position -173 and in 3 fragments of 206, 97, and $62 \mathrm{bp}$ in length for a C. Digested fragments were separated by electrophoresis on 2\% agarose gel and RFLP bands were visualized by ethidium bromide staining under UV light. The fragments of the PCR product were then sequenced.

\section{Statistical analysis}

The allele and genotype distributions were detected by Hardy-Weinberg equilibrium $(p>0.05)$. Data management and analysis were performed using Statistical Package for Social Sciences software, version 17.0 (SPSS, Inc., Chicago, IL, USA). Qualitative data were expressed as frequencies. The genotype and allele frequencies for asthmatic children and healthy control group subjects were analyzed using the $\chi^{2}$ test or Fisher's exact test. Normally distributed quantitative data were expressed as mean \pm standard deviation (SD) and differences between the patients and healthy control groups were assessed by Student's $t$-test, while data that were not normally distributed were expressed as the median and interquartile range and differences between the two groups were assessed by the Mann-Whitney test. Differences were considered statistically significant at $p<0.05$. Odds ratios (OR) with $95 \%$ confidence interval (CI) were used for estimating the relative risk for development of asthma. 


\section{Results}

Both asthmatic patients and controls were in HardyWeinberg equilibrium with MIF-173G/C genotypes' distribution $(p>0.05)$. No statistically significant differences were found between the asthmatic children and the healthy controls with regard to mean age, gender and body weight ( $p=0.867,0.13$ and 0.062 , respectively) (Table 1$)$. In 18 patients $(30 \%)$, serum IgE levels were significantly higher in children with bronchial asthma than in the healthy control group $(p=0.001)$.

In the two groups of asthmatic children and healthy controls, there were three kinds of genotypes - CC, CG and GG - and two types of alleles: C and G (Table 2).
There was a significant difference in the distribution of the CC genotypes in children with asthma and healthy controls $(p=0.028, \mathrm{OR}=6.24,95 \% \mathrm{CI}=1.24-31.29)$. No significant difference was observed for the GC genotype between the two groups. The distribution of the $\mathrm{C}$ allele was found to be significantly higher in asthmatic children than in healthy controls $(p=0.002, \mathrm{OR}=3.61,95 \% \mathrm{CI}=1.63$ 7.97). When carriage of the MIF-173C allele in children with asthma was compared with that observed in healthy controls ( $\mathrm{GC}+\mathrm{CC}$ vs. GG), it revealed a significant association with the risk of the disease $(p=0.019, \mathrm{OR}=3.12$, 95\% CI = 1.22-7.99) (Table 2).

No statistically significant relation was found between pediatric patients carrying the $\mathrm{C}$ allele and those who did

Table 1. Clinical and demographic characteristics of asthmatic children and healthy controls

\begin{tabular}{lccc}
\hline \multicolumn{1}{c}{ Characteristic } & $\begin{array}{c}\text { Asthma } \\
\mathbf{n = 6 0}\end{array}$ & $\begin{array}{c}\text { Controls } \\
\boldsymbol{n}=\mathbf{9 0}\end{array}$ & $\boldsymbol{P}$-value \\
\hline Age (years), mean $\pm \mathrm{SD}$ & $7.63 \pm 2.90$ & $7.71 \pm 3.10$ & 0.867 \\
\hline Age at onset (years), mean $\pm \mathrm{SD}$ & $3.88 \pm 3.10$ & & \\
\hline Gender, $n(\%)$ & & & 0.130 \\
\hline Male & $39(65.0)$ & $46(51.1)$ & 0.062 \\
\hline Female & $21(35.0)$ & $44(48.9)$ & 0.001 \\
\hline Weight $(\mathrm{kg})$, mean $\pm \mathrm{SD}$ & $28.98 \pm 14.50$ & $25.63 \pm 7.16$ & $30.5(15.6-53.0)$ \\
\hline Total serum IgE $(\mathrm{IU} / \mathrm{ml})$, median $(\mathrm{IQR})$ & $162.0(48.1-537.0)$ & & \\
\hline IgE- immunoglobulin $E ;$ IQR - interquartile range; $S D-$ standard deviation & & \\
\hline
\end{tabular}

Table 2. Frequency of MIF-173G/C alleles and genotypes of asthmatic patients and controls

\begin{tabular}{|c|c|c|c|c|}
\hline & Childhood asthma & Control & $P$-value & OR $(95 \%$ CI $)$ \\
\hline MIF-173 genotype & $n=60, n(\%)$ & $n=90, n(\%)$ & & \\
\hline GG & $46(76.7)$ & $82(91.1)$ & Reference & 1.00 \\
\hline GC & $7(11.7)$ & $6(6.7)$ & 0.237 & $2.08(0.66-6.56)$ \\
\hline $\mathrm{CC}$ & $7(11.7)$ & $2(2.2)$ & 0.028 & $6.24(1.24-31.29)$ \\
\hline $\mathrm{GC}+\mathrm{CC}$ & $14(23.3)$ & $8(8.9)$ & 0.019 & $3.12(1.22-7.99)$ \\
\hline Allele & $2 n=120, n(\%)$ & $2 n=180, n(\%)$ & & \\
\hline G & $99(82.5)$ & $170(94.4)$ & Reference & 1.00 \\
\hline $\mathrm{C}$ & $21(17.5)$ & $10(5.6)$ & 0.002 & $3.61(1.63-7.97)$ \\
\hline
\end{tabular}

Table 3. Demographic, clinical and laboratory data among patients with and without the $\mathrm{C}$ allele

\begin{tabular}{lccc}
\hline Parameter & $\begin{array}{c}\text { GG } \\
\boldsymbol{n} \mathbf{4 6}\end{array}$ & $\begin{array}{c}\text { GC }+\mathbf{C C} \\
\boldsymbol{n}=\mathbf{1 4}\end{array}$ & $\boldsymbol{P}$-value \\
\hline Age (years), mean \pm SD & $7.58 \pm 2.99$ & $8.22 \pm 3.0$ & 0.486 \\
\hline Age at onset (years), mean \pm SD & $3.55 \pm 2.60$ & $4.98 \pm 4.15$ & 0.126 \\
\hline Abnormal chest examination findings, $n(\%)$ & $41(89.1)$ & $11(78.6)$ & 0.374 \\
\hline Abnormal X-ray findings, $n(\%)$ & $15(32.6)$ & $7(50.0)$ & 0.343 \\
\hline Presence of other atopies, $n(\%)$ & $8(17.4)$ & $2(14.3)$ & 1.000 \\
\hline Eosinophilia, $n(\%)$ & $5(10.9)$ & $3(21.4)$ & 0.374 \\
\hline SD - standard deviation & & &
\end{tabular}


not, regarding the clinical and radiological data, presence of other atopies, or eosinophilia (Table 3).

\section{Discussion}

Given the role of MIF in innate immune responses against microbial pathogens and regulation of inflammatory responses, we hypothesized that common allelic variations in these potentially functional polymorphisms may be involved in the genetic-environmental interaction underlying the pathophysiology of asthma. Our findings showed that the MIF-173C allele and MIF-173CC genotype were associated with an increased risk of asthma in the pediatric patients $(p=0.002, \mathrm{OR}=3.61,95 \% \mathrm{CI}=1.63-7.97$ and $p=0.028, \mathrm{OR}=6.24,95 \% \mathrm{CI}=1.24-31.29$; respectively). Similarly, Wu et al. [14] observed a significant association between the MIF-173C allele and childhood asthma in a Chinese population. Other researchers [15] found no significant differences in genotype distribution of MIF-173G/C polymorphism between healthy control subjects and those with adult asthma, although they detected a significant association with atopy, while Mizue et al. [16] reported a significant association between mild asthma in adults and the low-expression allele MIF CATT . $^{\text {. }}$

Promoter sequence analysis indicates that the $-173 \mathrm{C}$ allele creates a potential activator protein- 4 transcription factor binding site and enhances the expression of MIF. Healthy individuals carrying the MIF-173C allele produce greater amounts of MIF protein compared with those with the MIF-GG genotype, and their serum MIF levels are significantly higher [8]. Furthermore, studies have shown that patients with severe asthma have higher serum MIF levels than those with mild asthma $[17,18]$. In a T-lymphoblast cell line transiently transfected by the MIF-173C variant, the $\mathrm{C}$ allele was found to be associated with significantly increased MIF expression [19].

MIF regulates innate immune responses by macrophages through modulation of expression of Toll-like receptor 4 (TLR4), the signal transducing molecule of the lipopolysaccharide (LPS) receptor complex [20]. A receptor complex consisting of the signaling subunit TLR4 and two accessory proteins, MD2 and CD 14, recognizes LPS and Gram-negative bacteria, so TLR4 is the principal receptor for bacterial endotoxin recognition. There is evidence that endotoxin exposure during early life is protective against development of atopy and asthma. It is hypothesized that bacterial signals, such as endotoxin, play a functional role in maturation of Th1 immune responses, suppressing the Th2 response [21]. MIF also plays an important regulatory role in the activation of $\mathrm{T}$-cells induced by mitogenic or antigenic stimuli. The strong induction of MIF messenger (m)RNA and protein has been observed from Th2 but not Th1 clones [12].

The variations in the results observed between adult and childhood asthma might be due to age-related genetic susceptibility, as various etiological factors play an important role in the pathogenesis of asthma, and their effects differ considerably with age [22]. For instance, genetic variations in the gene for death-associated protein-3 (DAP3) might be associated with the mechanisms responsible for the development of asthma in adults but not in children [23], while the C-C chemokine receptor 5 (CCR5) delta32 polymorphism is associated with reduced risk of asthma in children but not in adults [24]. Furthermore, the discrepancy in the results between various studies might be due to different distributions of the polymorphism in different races due to human evolution, ethnic-specific differences in environmental or genetic risk factors and different nationalities and geographic regions.

Total serum IgE is an asthma-related phenotype, and high levels of IgE are in accordance with the severity of asthma. Th2 cells secrete interleukin (IL)-4 and IL-13, which induce class-switch recombination of the variable region of IgE, leading to IgE expression [25]. Researchers found that mice genetically deficient in MIF had lower titers of specific IgE [16]. MIF promotes recognition of endotoxin-containing particles and Gram-negative bacteria by the innate immune system as microbial toxins potentially induce the release of MIF by immune cells and upregulate the expression of TLR4 in macrophages [26]. Studies suggest that lack of exposure to endotoxin in early childhood is a risk factor for the development of asthma [27]. Also polymorphisms in the genes encoding endotoxin-signaling molecules such as CD14 and caspase recruitment domain containing protein 15 (CARD15) have been observed to be associated with total serum IgE levels [28, 29]. This supports the hypothesis that exposure to endotoxin activates the innate immune system and modulates IgE regulation.

It is important to note that the case-control approach has an inherent potential for false-positive results due to differences in population stratification between cases and control subjects [30]. However, as both asthmatic patients and controls were in Hardy-Weinberg equilibrium with MIF-173G/C genotypes' distribution, and since we studied only one locus in an exclusively Egyptian population, problems associated with population stratification might be of little importance, with a limited effect on the present study.

\section{Conclusions}

Our present findings strongly support the hypothesis that children with MIF-173G/C polymorphism who carry the MIF-173C allele are at increased risk of developing asthma under certain environmental and genetic conditions. Additional evidence is needed from further studies with larger groups, including studies in other populations, together with evaluation of serum MIF levels and other functional studies, to elucidate the role of this polymorphism in the pathogenesis and development of asthma. 


\section{The authors declare no conflict of interest.}

\section{References}

1. Cave AJ, Atkinson LL (2014): Asthma in preschool children: a review of the diagnostic challenges. J Am Board Fam Med 27: 538-548.

2. Mukherjee AB, Zhang Z (2011): Allergic asthma: influence of genetic and environmental factors. J Biol Chem 286: 3288332889.

3. Nakagome K, Nagata M (2011): Pathogenesis of airway inflammation in bronchial asthma. Auris Nasus Larynx 38: 555-563.

4. Ishmael F (2011): The inflammatory response in the pathogenesis of asthma. J Am Osteopath Assoc 111 (11 Suppl 7): S11-17.

5. Lambrecht BN, Hammad H (2010): The role of dendritic and epithelial cells as master regulators of allergic airway inflammation. Lancet 376: 835-843.

6. Sauler M, Bucala R, Lee PJ (2015): Role of macrophage migration inhibitory factor in age-related lung disease. Am J Physiol Lung Cell Mol Physiol 309: L1-10.

7. Leng L, Chen L, Fan J, et al. (2011): A small-molecule macrophage migration inhibitory factor antagonist protects against glomerulonephritis in lupus-prone NZB/NZW F1 and MRL/ lpr mice. J Immunol 186: 527-538.

8. Ji K, Wang X, Li J, et al. (2015): Macrophage migration inhibitory factor polymorphism is associated with susceptibility to inflammatory coronary heart disease. Biomed Res Int 2015: 315174.

9. Park SJ, Lee YC (2010): Interleukin-17 regulation: an attractive therapeutic approach for asthma. Respir Res 11: 78.

10. Shimizu T, Hizawa N, Honda A, et al. (2005): Promoter region polymorphism of macrophage migration inhibitory factor is strong risk factor for young onset of extensive alopecia areata. Genes Immun 6: 285-289.

11. Bacher M, Metz CN, Calandra T, et al. (1996): An essential regulatory role for macrophage migration inhibitory factor in T-cell activation. Proc Natl Acad Sci U S A 93: 7849-7854.

12. Chen PF, Luo YL, Wang W, et al. (2010): ISO-1, a macrophage migration inhibitory factor antagonist, inhibits airway remodeling in a murine model of chronic asthma. Mol Med 16: 400-408.

13. Global Initiative for Asthma. Global Strategy for Asthma Management and Prevention, 2015. Available from: www. ginasthma.org.

14. Wu J, Fu S, Ren X, et al. (2009): Association of MIF promoter polymorphisms with childhood asthma in northeastern Chinese population. Tissue Antigens 73: 302-306.

15. Hizawa N, Yamaguchi E, Takahashi D, et al. (2004): Functional polymorphisms in the promoter region of macrophage migration inhibitory factor and atopy. Am J Respir Crit Care Med 169: 1014-1018.

16. Mizue Y, Ghani S, Leng L, et al. (2005): Role for macrophage migration inhibitory factor in asthma. Proc Natl Acad Sci U S A 102: 14410-14415.

17. Cooke G, Armstrong ME, Conroy H, Donnelly SC (2012): MIF and pulmonary disease. In: The MIF Handbook. Bucala R (ed.). World Scientific Publishing Co. Pte. Ltd. Singapore, Hackensack, London 2012; pp. 231-240.

18. Yamaguchi E, Nishihira J, Shimizu T, et al. (2000): Macrophage migration inhibitory factor (MIF) in bronchial asthma. Clin Exp Allergy 30: 1244-1249.
19. Donn R, Alourfi Z, De Benedetti F, et al. (2002): Mutation screening of the macrophage migration inhibitory factor gene: positive association of a functional polymorphism of macrophage migration inhibitory factor with juvenile idiopathic arthritis. Arthritis Rheum 46: 2402-2409.

20. Rosado Jde D, Rodriguez-Sosa M (2011): Macrophage migration inhibitory factor (MIF): a key player in protozoan infections. Int J Biol Sci 7: 1239-1256.

21. Douwes J, Pearce N, Heederik D (2002): Does environmental endotoxin exposure prevent asthma? Thorax 57: 86-90.

22. Le Souef PN (2006): Variations in genetic influences on the development of asthma throughout childhood, adolescence and early adult life. Curr Opin Allergy Clin Immunol 6: $317-$ 322.

23. Hirota T, Obara K, Matsuda A, et al. (2004): Association between genetic variation in the gene for death-associated protein-3 (DAP3) and adult asthma. J Hum Genet 49: 370-375.

24. Srivastava P, Helms PJ, Stewart D, et al. (2003): Association of CCR5Delta32 with reduced risk of childhood but not adult asthma. Thorax 58: 222-226.

25. Kemeny DM (2012): The role of the T follicular helper cells in allergic disease. Cell Mol Immunol 9: 386-389.

26. Roger T, David J, Glauser MP, Calandra T (2001): MIF regulates innate immune responses through modulation of Tolllike receptor 4. Nature 414: 920-924.

27. Gereda JE, Leung DY, Thatayatikom A, et al. (2000): Relation between house-dust endotoxin exposure, type $1 \mathrm{~T}$-cell development, and allergen sensitisation in infants at high risk of asthma. Lancet 355: 1680-1683.

28. Baldini M, Lohman IC, Halonen M, et al. (1999): A polymorphism* in the 5' flanking region of the CD14 gene is associated with circulating soluble CD14 levels and with total serum immunoglobulin E. Am J Respir Cell Mol Biol 20: 976-983.

29. Kabesch M, Peters W, Carr D, et al. (2003): Association between polymorphisms in caspase recruitment domain containing protein 15 and allergy in two German populations. J Allergy Clin Immunol 111: 813-817.

30. Haldar T, Ghosh S (2012): Effect of population stratification on false positive rates of population-based association analyses of quantitative traits. Ann Hum Genet 76: 237-245. 